\title{
Anti-seismic Research on External Thermal Insulation System
}

\author{
Yan Rongchun \\ Shandong water conservancy vocational college, \\ Shandong rizhao, 276826, china
}

Keywords: external thermal insulation system, anti-seismic research, facing tile

\begin{abstract}
The technological superiority for the external thermal insulation system was researched and analyzed in this paper. The anti-seismic protection standards and objective of the external thermal insulation system were proposed based on the anti-seismic programming principle of nonstructural components. Also the summary conclusion and suggestion for the anti-seismic performance of the external thermal insulation system were proposed finally. The anti-seismic analysis for the ordinary external thermal insulation tile was taken, and appropriate methods for improvement of the anti-seismic performance of the face brick thermal insulation system were proposed in the same time.
\end{abstract}

\section{Introduction}

Building energy conservation and the environmental protection maybe is the topic of common concern and the direction of the social development today ${ }^{[1-2]}$. In the energy consumption of the building, the external energy consumption occupies about 30 percent. The external thermal insulation of the building contains internal thermal insulation, external thermal insulation, and internal and external mixed thermal insulation and so on. The external thermal insulation means that to build the thermal insulation system on the outer side of the external wall for the purpose of thermal insulation. It is the construction method that makes the building in thermal insulation. The external thermal insulation system is constructed with thermal insulating layer, protection layer and fixing material, etc. And it is suited to install on the outer side of the external wall. The external thermal insulation system is not the loadbearing construction that just for the thermal insulation. The external thermal insulation system has the function such as insulation, energy saving, decoration, sound insulation effect and so on, it is a light and environmental system with non- bearing but protection function ${ }^{[3-4]}$.

\section{Basic requirements for seismic and fortification objectives}

The basic requirements for seismic for the external thermal insulation system.

According to the external thermal insulation system of the No.1 class of non structural members for the building, the balance of the safety and economy need to be taken in to consideration, so there are different levels of requirements and standards for the building seismic design code. Such as: (1) Class A standard: the exterior appearance can be damaged but it cannot affect the use function and fire protection ability. It can load more than 1.4 times of the deflection resulted from junction structure. (2) Class B standard: there is much stable performance of the application, and the maximum seismic force is less than 0.75 times of the original force in the normal area. (3) Class C standard: there is damage in most of the building body area, sometimes the damaged body need to be repaired. The seismic performance of the building body decreases greatly. It can load 0.6 times of the deflection of resulted from relevant structure.

\section{Fortification target of the external thermal insulation system.}

The fortification target of the external thermal insulation system is concluded based on the illustration of the Class A standard, class B standard and class C standard. That is: when the building is placed on the condition of frequent earthquakes, it reflects the elastic process in the structure from earthquake, there is less damage phenomenon for the building component 
and structure. When the building is placed on the condition of ordinary seismic intensity, the damage of the structure is in a certain domain. But the structural element of the external thermal insulation can tolerate much more damage than the building structure, and the performance of service and use need to be stable. Finally, when then building is placed in the region with scarce earthquakes, there is no damage for the structure and the external thermal insulation system may be damaged greatly but there is no falling.

Earthquake action for the seismic design of the external thermal insulation system.

1) Condition analysis of the seismic damage.

The earthquake action can damage the external wall body insulating layer interface, it shows as:

(1) Gress-Roots Wall

The interface bond damage is mainly concentrated between the base and the insulating layer. Before the insulation layer construction, the clean work is failed that makes the connecting force reduce between the insulation layer and roots layer. With the earthquake action, the whole insulation layer fall from Gress-Roots Wall layer.

(2) Interior of thermal insulation mortar

In the tile powder EPS insulation slurry particles system, the dead-weight of the ceramic tile is greater, but the intensity of the thermal insulation mortar has relative low strength. Therefore, it cannot bear the dead-weight and the shearing force from the earthquake action. The overlapping length of junction of the glass fiber cloth and wire mesh cannot satisfy the standards requirement. Sometimes, there is no overlapping phenomenon that leads the mechanical enhancement and connection performance to fail, this is the weakness of the insulating layer stress and the insulating layer will crack and fall from the ploy with the earthquake action.

\section{Analysis on the seismic force of external thermal insulation system.}

The seismic effects of the main structure of the building from the external thermal insulation system need to be analyzed before the analysis of the impact of the earthquake is taken. On the research of the seismic design for the main structure, the dead-weight of the external thermal insulation system needs to be analyzed deeply. But the external thermal insulation system is a type of flexible construction, so the effect of the rigidity to the main structure can be ignored. Secondly, the estimation of the self earthquake action should be taken into consideration particularly. The algorithm is showed as this: firstly, the force that the earthquake action power applied on the external thermal insulation structure, and the horizontal earthquake force along the horizontal direction. Secondly, on the normal conditions, the equivalent lateral force method can be applied in the nonstructural components gravity that produces the earthquake action.

Computational formula of horizontal earthquake action is:

$F=\gamma \eta \xi_{1} \xi_{2} \alpha_{\max } G$

Where the $F$ is the standard values of horizontal seismic action on the plot of the most unfavorable direction is applied to the member center. The $\gamma$ is the function coefficient of the components which is determined by the standards of the requirements of building fortification category. The value of $\gamma$ is $1.4,1.0$ or 1.6. The $\eta$ is the classification coefficient of anchor structure members. It has a strong correlation with the material properties and performance. The values range from 0.6 to 1.2 . $\xi_{1}$ is the state coefficient, $\xi_{1}=2.0$. The $\xi_{2}$ is the position coefficient of the building, the value is 2.0 on the apex of the building, and the value is 1.0 on the bottom of the building. $\alpha_{\max }$ is the maximum earthquake affecting coefficient, $\alpha_{\max }=0.9$ according to the scare earthquake condition. $G$ is the non-structural components value of the gravity load that is the external thermal insulation system self-weight .

\section{Combination of earthquake action and the other load for the external thermal insulation system.}

The chance of the effect of the wind load and on the external wall for the earthquake action that maximize to the maximal value is very small. So the effect of combination and assemble for each of the load need to be done in the analysis of the performance of the anti- 
seismic structure. The effect of the first variable action needs to be analyzed according to $100 \%$. The second variable action needs appropriate reduction. In the gravity load, wind load and seismic action, the limit state of bearing capacity planning needs to be done based on the fundamental combination assemble for the internal force from external thermal insulation system. The internal force of the planning value is going to be obtained. Then the most unfavorable combination is taken as the planning standard. Because the external thermal insulation system is contacting the outdoor environment directly, it is easy to be interfered and affected by the wind load. The effect of the wind load is greater than the seismic action effect, so the acting force need to be researched firstly, the combination coefficient is 1.0. Afterwards, the earthquake action is taken as secondary variable load. The uncertain combination coefficients are proposed in standard form, the value of combination coefficient is 0.5 according to the earthquake action in the curtain wall construction. When the control action is programmed according to the effect of permanent loads, sub coefficient is 1.35. But the variable action is limited to the vertical load, and the relevant combination coefficient should be taken into consideration.

Conclusions and suggestions for the external thermal insulation system.

(1) The damage of the external thermal insulation system always is secondary damage. The earthquake disaster always is showed as the damage to the main structure and the exterior protected construction. And it cannot equal the damage of the main body structure and the exterior protected construction to the damage of the insulation system.

(2) The High performance materials of the external thermal insulation system such as glass fiber cloth, anti-crack mortar, galvanized steel wire netting, etc. should be selected for the construction.

(3) The strict operation should be taken according to the relevant technical standards and procedures, such as the primary treatment, the anchorage depth, and the fiberglass cloth lap degree, etc.

(4) Seismic performance of the tile exterior insulation system is worse than the paint finish exterior insulation system. The tile mass per unit area should be restricted according to the relevant standard if use the tile of exterior insulation system.

Analysis on the facing brick anti-seismic safety of the external thermal insulation system.

According to the reality, the facing brick will get more damage in the earthquake. Compared with the paint finish, the facing brick has some advantages such as good durability, impact resistance of high strength, long life cycle, low price and convenient maintenance etc. So the facing brick anti-seismic safety of the external thermal insulation system is analyzed in this paper.

Currently, the facing brick is used as exterior wall finish in our country. It always has 3 types such as the adhesive polystyrene granule insulating material, the monolithic steel mesh polystyrene board and non-net poly-phenyl plate. The four angle galvanized wire is taken as the stuff of the seismic protection layer. The whole safety performance of the structure is improved based on enhancement of the binding fastness insulation layer and structure layer of the wall layer. Block diagram of the facing brick in the external thermal insulation system is showed as Figure 1. 


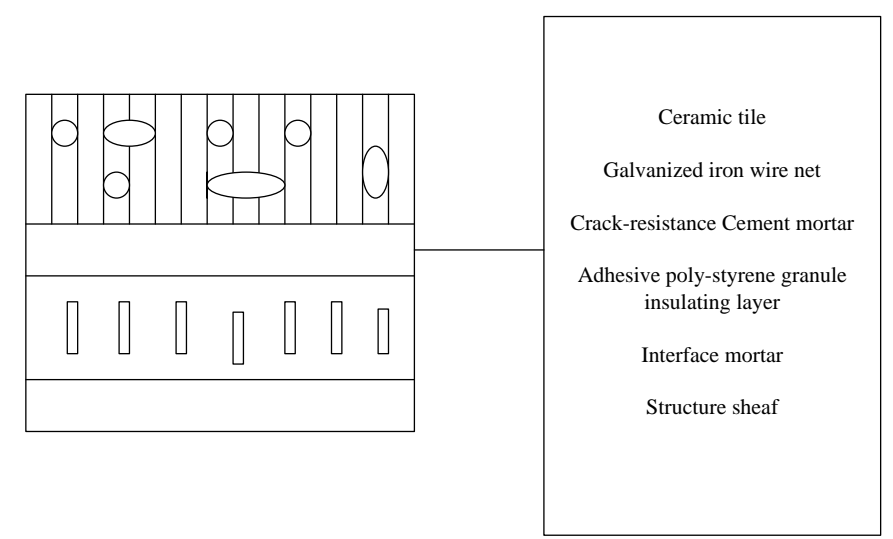

Figure 1. Block diagram of the facing brick in the external thermal insulation system

The adhesive polystyrene granule insulating material is taken as the heat insulating material. The reasonable construction technology is carried out to enhance the seismic performance of the facing the poly-phenyl granule of the external thermal insulation system. Two different of construction technology is taken ordinarily: (1) Smearing mortar interface and napping in the air for 24 hours after the pretreatment, and thermal insulation paste and mortar is dashed. (2) Smearing mortar interface and layering the thermal insulation mortar after the pretreatment.

\section{Measures of improving the facing brick anti-seismic safety in the external thermal insulation system.}

When the $\mathrm{l}$ face brick layer of the wall starts to crack and fall, the anti-seismic performance of the external thermal insulation system will be influenced. The main reasons of the cracking and falling as follows: (1) Temperature deformation. Because of the changing of the Internal and external wall temperature, results that the facing brick is interfered by the three-dimensional temperature stress. The stress raisers are formed on the finish coat and lead the falling to happen. (2)The integrity of the building decorative tile adhesive layer is destroyed because of the repeated freeze-thaw effect that causes the falling. (3) Tile falling caused by external force. Such as building wall deformation because of the irregular dislocation of the base, that makes the facing brick fall. For this, several factors as follows should be taken into consideration foe enhancement of the facing brick anti-seismic performance:

\section{Weight and size of the facing brick.}

According to the relevant information and material, the unit area of tile quality is less than or equal to $20 \mathrm{~kg}$ per square meter. The biggest single size is less than or equal to $30 \mathrm{~cm}$. Area of each facing brick is not more than $0.09 \mathrm{~m}^{2}$, the thickness is not more than 14ram, Stripshaped dovetail groove should be taken as the back groove shape of the facing brick. These norms will improve the seismic performance and stability of the external thermal insulation system.

\section{Bonding material tile of the facing brick.}

The dead-weight of the facing brick external thermal insulation system is higher than paint finish external thermal insulation system based on the experience. There are positive correlation between the dead- weight of the facing brick, tensile bond strength of the binder and ensile bond strength of the coating system. So the various ancillary materials should be had in the system, the performance should conform to the technical requirements.

\section{Protective anti-crack layer of the external thermal insulation system.}

The anti-crack mortar and the mortar composite strengthening net always are the protective anti-crack layer of the external thermal insulation system. Fiberglass mesh cloth not only can improve the protective layer of the tensile strength but also can dispersive stress. It also can reduce the probability of crack width. There is greater correlation property between the long-term resistances to alkali glass fiber cloth and the property of the anti-crack wall 
fracture of the wall body. The life cycle of the building wall is increased greatly. So the grid cloth should be used in the system.

There is some weakness for the cement-sand mortar such as high strength, high toughness and low shrinkage, etc. it cannot be taken as the stuff for the thermal insulation layer. Particularly, the anti-crack mortar combined with enhance network and fiber can be used here. But the compressive strength of anti-cracking mortar is greater than or equal to 3 . If the exterior facing is facing brick, the steel wire mesh can be mixed in the fiber-enhanced mortar. But the steel wire mesh must be uniform.

\section{Fixed method of the external thermal insulation system.}

For the safety of the tile of exterior wall external thermal insulation system, it needs to be fixed with the sticky nail fusion method. The rivets should be fixed behind the enhanced grid layer for the stability of bond state. If the dead-weight of the coating of exterior wall external insulation system is $10 \mathrm{~kg}$ per $\mathrm{m}^{2}$, then there is no need to analyze the blade load between each material layer only to guarantee the bonding of the stable of the base layer.

\section{Construction quality of the external thermal insulation system.}

(1) Paste area of the tiles: It is ensured that the real area of paste reached $100 \%$ in the back of the tile but without inter-spaces. If there are inter-spaces the ceramic tile will fall with the freeze thawing resulted from the water vapor.

(2) Paste time of the tiles: It's better to delay the past time of the tiles, because the alkali corrosion effect will be improved for the retardation of the mortar hydration. There are high correlations between the deformation properties of the facing brick external thermal insulation system and the drying time of the plastering mortar. The shrinkage of mortar is restricted to the tile stiffness, so the tiles need to be pasted after the contraction distortion to the plastering mortar. The time always is 7days, and it is need to be protected carefully in the time. And it is avoided that to stickup ceramic tile on the next day of smearing the mortar.

(3) The nodal points processing such as expansion joints, the corner of wall, doors and windows. The problem of waterproof and thermal bridge should be taken more into consideration on expansion joints. For the corner of wall, doors and windows close positions, the GT-1 GROUT with more flexibility need to be taken here. Because the deformation value is maximum on these position. In addition, the special angle tile and brickwork joint should be programmed on the turn of the external wall corner.

\section{Conclusion}

The effect of the structural elements and the effect of the earthquake action to the self system should be taken into consideration in design of the external thermal insulation system. The technical advantages of the external thermal insulation system were analyzed. The seismic safety standards and objectives were proposed for the external thermal insulation system based on the seismic planning principle of non-structural element. The conclusions and suggestions of the seismic performance in external thermal insulation system were presented in the same time. The seismic performance of the external thermal insulation tiles was analyzed and the seismic safety of the facing tile in the system was analyzed. The measures of the seismic performance of insulation system were proposed finally.

\section{References}

[1] LIAO Zhi-qiang, Li Tai-fu, YU De-jun, etal. Short- Term Wind Speed Forecasting of Neural Network Based on Phase Space Reconstruction[J]. Journal of Jiangnan University( Natural Science Edition), 2012, 11(1):14-18.

[2] Terrill Philip Lan, Wilson Stephen James, Suresh Sadasivam, et al. Attractor structure discriminates sleep states: Recurrence plot analysis applied to infant breathing patterns [J]. IEEE Transactions on Biomedical Engineering, 2010, 57(5): 1108-1116. 
[3] E. Bautista-Thompson, Moussavi Zahra. Swallowing sound detection using hidden markov modeling of recurrence plot features[J]. Chaos, Solitons and Fractals, 2009, 39(2): 778-783.

[4] LU Yong, XU Jinwu, LI Yourong. Application of Recurrence Plot and Approximate Entropy on complexity Analysis of Machinery Fault Signal[J]. Journal of Mechanical Strength. 2006, 28(3): 317-321. 